\title{
Florence Hulak, Sociétés et mentalités. La science historique de Marc Bloch. Paris: Hermann, 2012, 352 págs.
}

En una época en la que la mayor parte de la crítica da por concluida la "historia de las mentalidades” - como lo anunciaba G. E. R Lloyd en 1996 -, la filósofa Florence Hulak propone volver a considerar los hallazgos del historiador francés Marc Bloch sobre dicho asunto, explorando con riguroso método uno de los aspectos más notables de los trabajos de este autor: tomar en consideración en el análisis histórico los mecanismos sociales y, sobre todo, sus imperfecciones. Este libro, resultado de una tesis en Filosofía, realiza una mirada poco habitual, aunque muy dinámica, sobre la epistemología "blochiana" en el panorama de los estudios de los años treinta del pasado siglo XX.

El punto de partida de este estudio es la crítica que el filósofo Jacques Rancière dirige a la historia de los Annales, a la que califica de "republicano-romántica”. La autora se opone a tal consideración recordando que la revista Annales d'histoire économique et sociale, creada en 1929 por Lucien Febvre y Marc Bloch, mostró una gran motivación a la hora de renovar en profundidad la ciencia histórica, promoviendo una nueva historia que incluía las demás ciencias humanas - y, entre otras, la sociología de Émile Durkheim. La historia de los Annales contribuyó de hecho a la caída de lo que François Simiand llamaba los "tres ídolos" de los historiadores, esto es, la política, el individuo y la cronología. Tomar en cuenta los hechos sociales en su globalidad sin transformar la historia en una "sociología dinámica”, tal fue - según defiende Hulak - el reto de Lucien Febvre y Marc Bloch.

En unas páginas de gran claridad intelectual, Hulak sintetiza el "pensamiento psicológico" común de estos dos historiadores, basado en la necesaria toma en consideración de las modificaciones de la estructura mental que separan la época del historiador de la de los hechos analizados. El enfoque epistemológico de Febvre y Bloch incluye de hecho un imprescindible distanciamiento del historiador y de sus categorías de pensamiento a modo de condición sine qua non de la objetividad científica del trabajo historiográfico. Existe pues un trabajo previo del historiador que se hace psicólogo para lograr evidenciar "las herramientas mentales" de la época que estudia. La autora evidencia así la unidad teórica mínima entre estas dos aproximaciones, es decir, la estrategia de integración de la historia en el campo contemporáneo de las ciencias humanas.

Sin embargo, más allá de esta comunidad de pensamiento entre Febvre y Bloch, Florence Hulak subraya (en la primera parte, "Histoire, psychologie et herméneutique") aquello que opone a los dos autores: aunque ambos ambicionan una "historia total" capaz de dar cuenta de todos los aspectos de una sociedad - abriendo así paso a una historia de las mentalidades -, lo hacen desde perspectivas casi opuestas. La exploración de las mentalidades representa para Febvre un ejercicio de psicología histórica. El término 
"mentalidades", que toma prestado del psicólogo Charles Blondel, designa para él el sistema de las representaciones de una época, definido como un conjunto de categorías de la sensibilidad, la expresión y la conceptualización; este universo mental colectivo no se puede alcanzar en el pensamiento de Febvre sino de forma regresiva a partir de realizaciones individuales. De ahí que éste privilegie metodológicamente la biografía histórica, en la que el historiador pretende remontarse desde la obra hasta sus condiciones de posibilidad.

Marc Bloch, por su parte, se distancia en seguida del acercamiento individualista de Febvre y estudia los sistemas de pensamiento colectivo a partir del análisis de los ritos y de las prácticas simbólicas; así, en Les rois thaumaturges (1924), el historiador considera un objeto científico la creencia en el toque sanador de los reyes, al que propone analizar como una realidad social, esto es, vinculando dicha creencia con un contexto socio-político.

Así pues, para Lucien Febvre el "individuo" es el punto de partida de la estructura social, mientras que para Marc Bloch este mismo "individuo" es el producto de dicha sociedad. La síntesis sociológico-antropológica de Bloch (p. 110) se opone pues a la psicología hermenéutica de Febvre (p. 67).

En la medida en que Bloch y Febvre proponen análisis diferentes de fenómenos análogos, se podría pensar que la noción de "historia de las mentalidades" iba a construirse incorporando estos dos métodos diferentes de realización de un mismo objetivo. Pero Florence Hulak explica que esta diferencia no apareció claramente porque estos dos métodos no se desarrollaron al mismo nivel. A partir de los textos teóricos elaborados por ambos historiadores, la autora subraya que se tendió a identificar la "historia de las mentalidades" con la definición "febvriana", pero que, por lo que se refiere a la realización práctica, sólo pareció pertinente la definición "blochiana”. Las dos definiciones entraron pues en concurrencia y así explica Hulak la confusión definitoria de la noción de "historia de las mentalidades”. Ese carácter equívoco explicaría en gran medida la desaparición de esta categoría de pensamiento en los estudios históricos.

Pero más allá de esta hipótesis sobre la actual suerte de la "historia de las mentalidades", la confrontación detallada de estas dos aproximaciones le permite a Hulak exponer el "nuevo paradigma de Marc Bloch" (p. 115): la autora detalla la interpretación psicológica del historiador y presenta la concepción de la historia que éste defendía, a saber, la historia entendida como "maneras de sentir y de pensar" (p. 136), subrayando no obstante en el acto los límites de esta explicación causal. En unas pocas pero intensas páginas, Hulak explica cómo en la concepción "blochiana" de la historia cada sociedad se determina por el desorden causado por la presencia de estructuras antiguas y nuevas y por la contradicción entre los discursos y las prácticas. Dicho en otros términos, la ciencia histórica de Marc Bloch se define, ante todo, como una ciencia del desorden, que Hulak llama también "ciencia de los desfases” (p. 241). Tal es, según la filósofa, la mayor originalidad de la ciencia histórica de Marc Bloch.

Para recalcar mejor esta originalidad, la autora propone un recorrido por las lecturas críticas de dos obras fundamentales de Bloch: La société féodale (1939) y Apologie pour ISSN 2174-4289 
l'histoire (1941). Ésta vuelve a analizar las conclusiones de Ricoeur - y su "hermenéutica psicológica" - sobre dichas obras, diferencia la aproximación "blochiana” de la concepción "althusseriana" de la historia, y examina de forma muy erudita la herencia del primer y del segundo durkheimismo en el "método comparativo" desarrollado por Bloch. El cotejo de La société féodale con las tesis del mayor representante de la segunda generación de los “durkheimianos", Marcel Mauss, da lugar a una reflexión sobre la "síntesis antropológica" de Bloch, sobre su concepto de "tonalidad social" (p. 211), el cual es definido como un conjunto de instituciones muy variadas, de muy diversas épocas, que pueden funcionar juntas porque se "tocan" todas en un mismo tono capaz de armonizarlas. Este tipo de armonización se ejemplifica con la evocación de cómo se produce el paso del señorío al feudalismo.

A continuación Hulak pormenoriza el proceso de síntesis histórica construido por la pluma de Marc Bloch, porque el trabajo de análisis de los “fenómenos aparentados" debe prolongarse con una reconstitución sintética de la experiencia vivida (p. 208). En efecto, Bloch reconstituye la sociedad feudal a partir de vínculos humanos vividos como personales. Así, por ejemplo, el cumplimiento de un rito de homenaje “por poderes” era imposible ya que el vínculo social no se podía separar del contacto, casi físico, que el acto de homenaje establecía entre dos hombres. Pero el interés de Bloch por el hecho social va más allá y se extiende al análisis de las mentalidades, incluyendo consideraciones de "percepción”. Hulak explica que esta posición intelectual permite a Bloch dilucidar ciertos elementos históricos que no se podían explicar hasta entonces: entre otros, los mitos políticos (el ciclo artúrico, la vida del rey Salomón muerto y la epopeya, pp. 216-231). Entendemos, al leer estas páginas, que las epopeyas son mitos históricos que prefiguran la dimensión mítica de la ciencia histórica moderna sin poseer el modo científico de regulación (p. 224). Interesa subrayar también que Bloch no concibe los mitos y la literatura que los arrastra como el reflejo de las tendencias morales reales de la sociedad, sino que invierte esta lectura e interpreta el apogeo de la explotación simbólica de un ideal como el síntoma de su decadencia social. No existe pues una correlación directa entre el mito y la práctica. Así que, para entender una sociedad, el historiador tiene que recurrir a sus mitos y subrayar de ese modo el desfase de las mismas respecto a las prácticas sociales a las que dicha sociedad da sentido.

La noción de síntesis histórica se ve pues atravesada por una tensión constitutiva: no puede sino realizarse desde el punto de vista del sentido, pero éste siempre está desfasado con respecto a las prácticas que intenta significar. Y esa es la especificidad de la ciencia histórica con respecto a la sociología o la antropología: el estudio de los desfases. Marc Bloch afirmó repetidas veces que ninguna sociedad es lo bastante homogénea ni estable como para dejarse reducir a un principio sintético global ("toda sincronía es aparente", p. 237). De ser así, no habría cambio posible. La noción de “desfases” predomina por lo tanto en la última parte del estudio de Hulak (“desfases e historicidad”). La consecuencia directa de tal concepción de la historia es que el historiador no puede analizar una sociedad como si fuera inmutable; su papel es destacar los desfases que subyacen en ella y que le dan su movimiento. De la ciencia histórica de Bloch, que muestra la existencia de desfases entre 
los diferentes tipos de fenómenos, se puede inducir un nuevo concepto de desfase entre lo mental y lo social.

En efecto, aunque de Les rois thaumaturges a La société féodale el historiador francés hace suya la ambición propiamente explicativa de las ciencias sociales, también admite que la materia histórica no se deja ordenar por completo. La historia "blochiana" se concentra sobre lo que resiste a la comprensión sintética del pasado, a los desfases temporales e ideológicos que revelan los límites de toda estructuración simbólica. Se desbarata así la oposición estéril entre estructuras e historicidad y se concibe entonces el papel político del historiador como la introducción de "desfases" dentro de los relatos memoriales para mejor entender su sentido. Dicho de otro modo, este desajuste determina el estatuto de la acción humana en la historia (p. 242). El desorden, que se define no como un caos sino como "coexistencia de sistemas heterogéneos" (p. 245), viene a ser para Bloch por lo tanto el "gran hecho histórico". Este concepto, bastante difícil de abarcar, lo indaga Hulak a través de varios historiadores - Durkheim, Halbwachs... - para ver cómo cada uno de ellos intentó resolver el aparente dilema y para analizar mejor cuál fue la "solución" de Bloch. Mediante este concepto de "desajuste”, la autora logra ilustrar cómo la historia de Bloch alcanza sus objetivos y permite dibujar un retrato dinámico de las sociedades humanas. Estos desfases identificados por el historiador son, de hecho, los motores de la historia. Según la autora, tomar la vía epistemológica abierta por la obra de Bloch no sólo permite renovar el pensamiento sobre la ciencia histórica contemporánea, sino también volver a considerar la cuestión de la subjetividad en la historia (p. 310). Permite, entre otras cosas, interrogar el compartimiento de los paradigmas históricos propuestos por Jacques Rancière y volver a pensar el vínculo entre estructuralismo e historia. Con estos últimos argumentos, Florence Hulak intenta reconciliar de alguna manera el enfoque de Bloch con la filosofía de Rancière a que hace referencia en el inicio de su estudio.

Sophie Hirel-Wouts

Université Paris Est/Marne-la-Vallée. France

sophie.hirel@laposte.net

Fecha de recepción: 20 de mayo de 2013

Fecha de aceptación: 12 de junio de 2013

Publicado: 15 de junio de 2013

Para citar: Sophie Hirel-Wouts, "Florence Hulak. Sociétés et mentalités. La science historique de Marc Bloch. Paris: Hermann, 2012, 352 pags.”, Historiografías, 5 (enero-junio, 2013): pp. 135-138,

http://www.unizar.es/historiografias/historiografias/numeros/5/hirel_res.pdf 